\title{
Phasmomantella gen. nov., a spectacular new genus of praying mantis from southern Central Vietnam (Mantodea, Mantidae, Deroplatyinae, Euchomenellini)
}

\author{
Xavier H.C. VERMEERSCH \\ Royal Belgian Institute of Natural Sciences, O.D. Phylogeny and Taxonomy, Entomology, \\ Vautierstreet 29, B-1000 Brussels, Belgium. \\ Email : xavier.vermeersch@outlook.com
}

urn:1sid:zoobank.org:author:8C98D5BE-D019-4115-91C1-4C820643638D

\begin{abstract}
The new genus Phasmomantella gen. nov. is created to accommodate the new species $P$. nuichuana gen. et sp. nov. described from five adult females from Núi Chúa National Park in southern Central Vietnam. A second species, Phasmomantella pallida (Roy, 2001) gen. et comb. nov., is transferred from Euchomenella where it was originally described based on a single male specimen from the Nha Trang region in the Khánh Hòa Province. Phasmomantella gen. nov. is placed in the tribe Euchomenellini of the subfamily Deroplatyinae. A comprehensive diagnosis and detailed descriptions are presented along with high-resolution photographs, measurements and a distribution map. The standardised measurements are illustrated and a new key is proposed for the tribe Euchomenellini. The unique biogeography and habitats of the collection site within Núi Chúa National Park are discussed in the light of possible endemism and importance for nature conservation.
\end{abstract}

Keywords. Núi Chúa National Park, nuichuana, pallida, stick mantis, Global Taxonomic Initiative.

Vermeersch X.H.C. 2018. Phasmomantella gen. nov., a spectacular new genus of praying mantis from southern Central Vietnam (Mantodea, Mantidae, Deroplatyinae, Euchomenellini). European Journal of Taxonomy 442: 1-17. https://doi.org/10.5852/ejt.2018.442

\section{Introduction}

The examination of mounted specimens of Mantodea Burmeister, 1838 collected within the framework of the Global Taxonomic Initiative project 'A step further in the entomodiversity of Vietnam' revealed the need to erect a new genus to include a new species of praying mantis from southern Central Vietnam. A morphological analysis of the specimens places this new genus and species within the exclusively oriental tribe Euchomenellini Giglio-Tos, 1916 of the subfamily Deroplatyinae Westwood, 1889. A differential diagnosis with the other genera of the tribe Euchomenellini, Euchomenella (GiglioTos, 1916), Indomenella (Roy, 2008) and Tagalomantis (Hebard, 1920), was performed. The studied specimens feature sufficient distinctive characteristics that do not correspond to standing generic descriptions to justify the creation of a new genus and species. The present paper aims to describe the new genus Phasmomantella gen. nov. to contain P. nuichuana gen. et sp. nov. and Phasmomantella pallida (Roy, 2001) gen. et comb. nov. based on morphological characteristics. 


\section{Material and methods}

\section{Field collecting and preparation}

All specimens of $P$. nuichuana gen. et sp. nov. were collected at night by visual inspection of the vegetation between ground- and eye level using a light-weight and water-proof Petzl MYO RXP head torch. The specimens were euthanized by etylacetate fumes shortly after capture and then stored in airtight plastic 'zip'-bags, embedded in fine wood chips (as those used in rodent cages) and sprinkled with etylacetate (EtOAc) to prevent rotting, moult growth and to keep the specimens flexible during storage and transport. The bags were frozen at $-18^{\circ} \mathrm{C}$ upon arrival and the specimens were mounted at a later time.

\section{Illustrations}

Photographs were taken with a Canon EOS 700D DSLR camera mounted with a Sigma AF $50 \mathrm{~mm} f / 2.8$ EX DG macro lens and two Yongnuo Speedlite YN 460-II off-camera flashes. The photographs were processed in Adobe ${ }^{\circledR}$ Photoshop CS 5.5 to adjust levels and to perform image alignment and stacking. The stacked images were then optimised using Adobe ${ }^{\circledR}$ Photoshop Lightroom 6 to adjust exposure and sharpness. Minor adjustments were also made using the spot removal tool to correct for distracting debris.

\section{Descriptive conventions and observations}

The morphological nomenclature follows Wieland (2013) and Brannoch et al. (2017), measurements build further on Svenson (2014) and Brannoch et al. (2017). For the generic-level-comparison with Euchomenella, Indomenella and Tagalomantis, the external morphology was directly compared with types and representative specimens from the entomological collections of RBINS and MNHN, and the original descriptions in the primary literature (Ghate \& Mukherjee 2004; Giglio-Tos 1916, 1927; Hebard 1920; Roy 2001, 2008; Schwarz 2017).

The formula to express the spine count of the raptorial legs follows Brannoch et al. (2017). The formula is divided into a femoral (F) and a tibial (T) section, which detail the number and potential variability of the discoidal spines (DS), anteroventral spines (AvS) and posteroventral spines (PvS). The spine formula is written as $\mathrm{F}=\mathrm{DS} / \mathrm{AvS} / \mathrm{PvS} ; \mathrm{T}=\mathrm{AvS} / \mathrm{PvS}$. Neither the femoral genicular spurs nor the tibial spur are included in the spine count. Spine numbering is always performed from the proximal end towards the distal end. Profemoral spine size arrangement is represented using the letter ' $\mathrm{I}$ ' in a font size relative to the spine size within the arrangement and given from the proximal to the distal end.

Observations were done using a Leica MZ8 stereo microscope. The description of the colouration is based on mounted specimens. All measurements are in millimetres and were taken with an electronic calliper. For paired appendages, the given value represents the mean of both measurements with exception of the tegmina where only the overlapping tegmen is taken into account. If one of the appendages is missing, broken or clearly deformed, then only the intact one is used (if available). Twenty-two measurements were taken (as illustrated on Fig. 1) and recorded (Tables 1-2).

\section{Measurements}

\section{Length/width}

- Total length (TL) = from the most anterior margin of the head to the posterior tip of the abdomen; for general size estimation

- Head width $(\mathrm{HW})=$ distance between the external margins of the eyes at the widest point

- Head height $(\mathrm{HH})=$ distance between the tip of the labrum and the top of the vertex

- Pronotum length $(\mathrm{PL})=$ from the anterior to the posterior margin of the pronotum

- Pronotum width $(\mathrm{PW})=$ distance between the lateral margins of the pronotum at the widest point 
- Pronotum narrow width $(\mathrm{PnW})=$ distance between the lateral margins of the pronotum at the narrowest point of the metazone

- Prozone length $(\mathrm{PzL})=$ from the anterior margin of the pronotum to the centre of the supra-coxal sulcus

- Metazone length $(\mathrm{MzL})=$ from the centre of the supra-coxal sulcus to the posterior margin of the pronotum

- Tegmen length $(\mathrm{TgL})=$ from the proximal margin of the axillary sclerites to the distal tip of the discoidal region

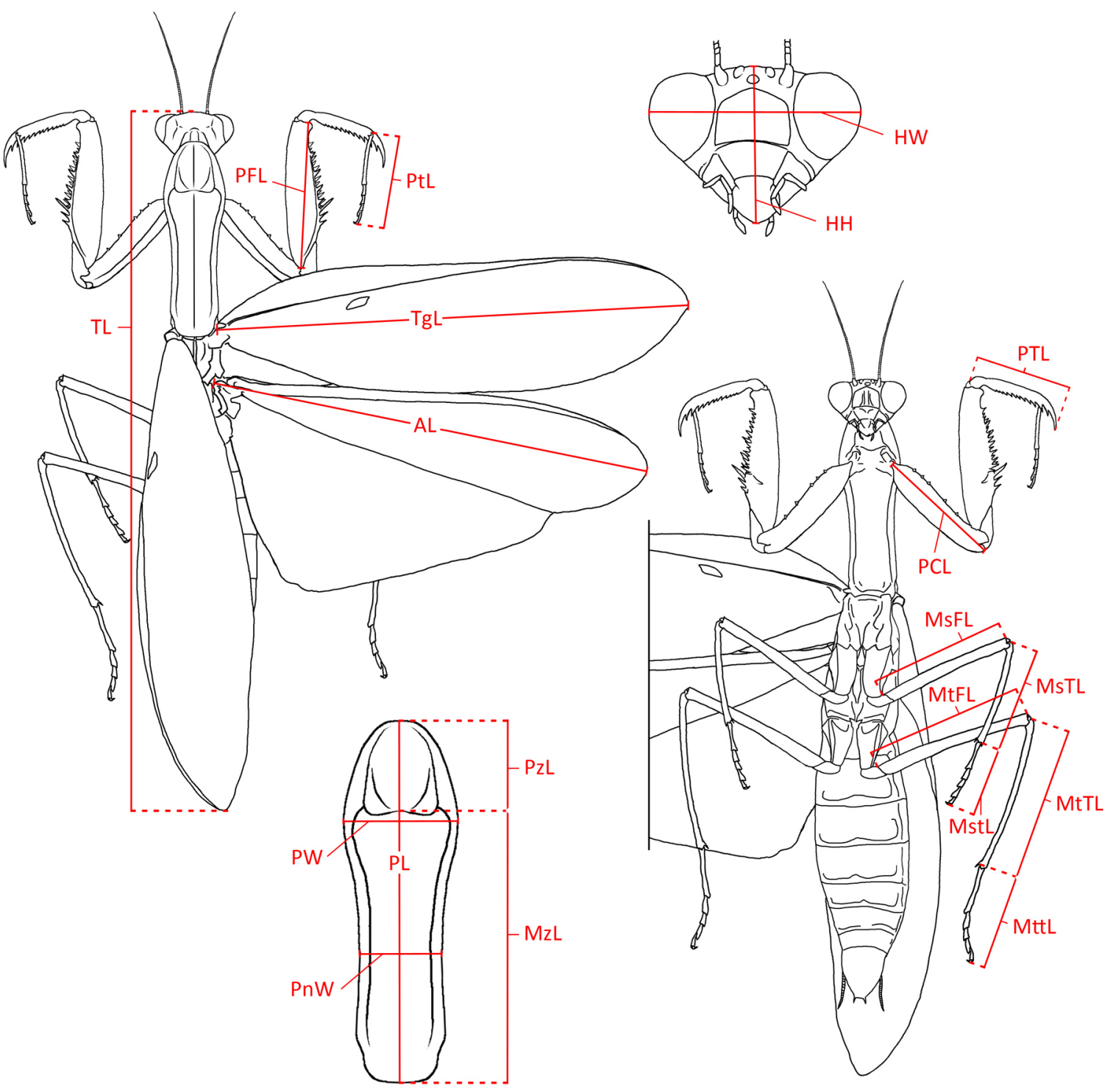

Fig. 1. Overview of the measurements on the habitus of Hierodula spp. Head (top right): HW = head width; $\mathrm{HH}=$ head height. Dorsal view (left): $\mathrm{TL}=$ total length; $\mathrm{PFL}=$ profemur length; $\mathrm{PtL}=$ protarsus length; $\operatorname{TgL}=$ tegmen length; $\mathrm{AL}=$ ala length. Ventral view (right): $\mathrm{PTL}=$ protibia length; $\mathrm{PCL}=$ procoxa length $\mathrm{MsFL}=$ mesofemur length; $\mathrm{MsTL}=$ mesotibia length; $\mathrm{MstL}=$ mesotarsus length; $\mathrm{MtFL}=$ metafemur length; $\mathrm{MtTL}=$ metatibia length; $\mathrm{MttL}=$ metatarsus length. Pronotum (bottom left): $\mathrm{PL}=$ pronotum length; $\mathrm{PzL}=$ prozone length; $\mathrm{MzL}=$ metazone length; $\mathrm{PW}=$ pronotum width; $\mathrm{PnW}=$ pronotum narrow width. 
- Ala length $(\mathrm{AL})=$ from the proximal margin of the axillary sclerites to the distal tip of the discoidal region

- Post-Pronotum Body Length $(\mathrm{PPBL})=$ Represents the distance between the posterior margin of the pronotum and the apex of the abdomen; it serves to easily assess the degree of abdomen coverage by the tegmina and alae for short winged species

- Procoxa length $(\mathrm{PCL})=$ from the proximal joint to the distal margin of the ventral coxal lobe

- Profemur length $(\mathrm{PFL})=$ from the proximal margin (adjacent to the trochanter) to the distal margin of the genicular lobe

- Protibia length $(\mathrm{PTL})=$ from the proximal joint to the apex of the tibial spur

- Protarsus length $(\mathrm{PtL})=$ from the proximal joint of the first tarsomere to the apex of the claw

- Mesofemur length $(\mathrm{MsFL})=$ from the most proximal margin adjacent to the trochanter to the distal side of the genicular spur insertion site

- Mesotibia length $($ MsTL $)=$ from the proximal joint with the femur to the distal side of the tibial spur insertion site

- Mesotarsus length $(\mathrm{MstL})=$ from the proximal joint of the first tarsomere to the apex of the claw

- Metafemur length $(\mathrm{MtFL})=$ from the most proximal margin adjacent to the trochanter to the distal side of the genicular spur insertion site

- Metatibia length $(\mathrm{MtTL})=$ from the proximal joint with the femur to the distal side of the tibial spur insertion site

- Metatarsus length $(\mathrm{MttL})=$ from the proximal joint of the first tarsomere to the apex of the claw

\section{Spine count}

- Anteroventral profemoral spine count $=$ all inner marginal spines (discoidal spines not included)

- Anteroventral protibial spine count $=$ all inner marginal spines (tibial spur not included)

- Posteroventral protibial spine count $=$ all outer marginal spines (tibial spur not included)

\section{Abbreviations}

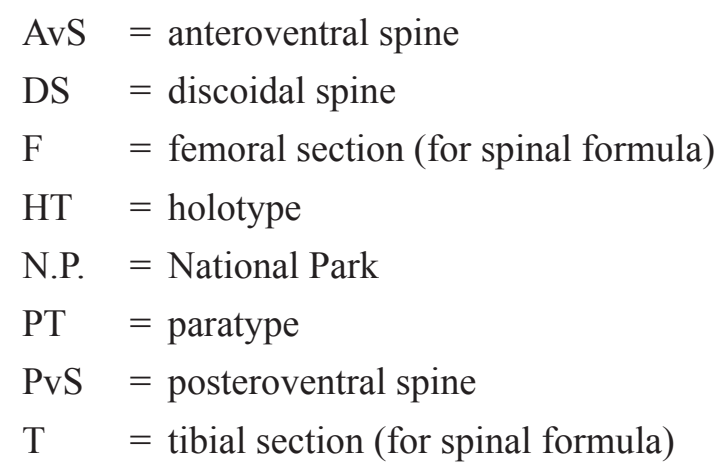

\section{Institutional acronyms}

MNHN = Muséum national d'Histoire naturelle, Paris, France

RBINS = Royal Belgian Institute of Natural Sciences, Brussels, Belgium

VNMN = Vietnam National Museum of Nature, Hanoi, Vietnam 


\title{
Results
}

\author{
Order Mantodea, Burmeister, 1838 \\ Family Mantidae Burmeister, 1838 \\ Subfamily Deroplatyinae Westwood, 1889 \\ Tribe Euchomenellini Giglio-Tos, 1916
}

The tribe Euchomenellini as reinstated by Schwarz (2017) is redefined by the following combination of characters: head broader than high, without process; lower frons not keeled; legs without lobes; tibial spur groove in distal half of profemur; pronotum slender and very elongate, without lateral cuticular expansions; tegmina in females shorter or equal to half the PPBL, reaching as far or beyond the abdominal apex in males; alae completely covered by tegmina; tergite 10 (= supra-anal plate) without median lobe; cerci not flattened.

\section{Key to the genera of Euchomenellini}

The following key is mostly based on the external morphological characters of females which are easily distinguishable in Euchomenellini and builds further on the key for Deroplatyinae proposed by Schwarz (2017).

1. Protibiae with at least 10 posteroventral spines; prominent tubercles behind the supra-coxal sulcus Tagalomantis (Hebard, 1920)

- Pronotum entirely smooth .

2. Protibiae with seven or eight posteroventral spines. Females: pronotum shorter than the remaining body; alae blackish brown with white transverse veinlets

Indomenella (Roy, 2008)

- Protibiae with seven posteroventral spines. Females: pronotum equal in size or longer than the remaining body

3. Inner side of profemora transversely crossed by two broad and well-defined darker bands; darkened area near the distal end of the procoxae (Fig. 2A). Females: tegmina very short, less than half the post-pronotum body length; alae under-developed or almost scale-shaped, colour pale white, yellowish or slightly enfumated (Fig. 2C). Males: tegmina reaching as far or beyond the abdominal apex at rest, brownish enfumated and gradually darker near the apex; alae well developed, same colour as tegmina ..........................Euchomenella (Giglio-Tos, 1916)

- Inner side of profemora with only one dark spot distally adjacent to the tibial spur groove (Fig. 2B). Females: tegmina about half as long as the post-pronotum body length; alae fully covered by tegmina but normally shaped, entirely hyaline (Fig. 2D). Males: tegmina reaching as far as the abdominal apex at rest, tegmina and alae entirely hyaline

Phasmomantella gen. nov.

\section{Genus Phasmomantella gen. nov. urn:lsid:zoobank.org:act:56B7A1C1-0E73-4764-80C7-6A241A59DFEF}

\section{Type species}

Phasmomantella nuichuana gen. et sp. nov. by present designation.

\section{Diagnosis}

Compound eyes globular, frontally and laterally bulging. Cranial vertex flat. Antennae filiform. Pronotum smooth, narrow without lateral cuticular expansions and longer than remaining body in females. Procoxae much shorter than pronotum. Profemora with four discoidal spines and four posteroventral spines of 
which the $3^{\text {rd }}$ spine is the longest. Spinal formula: $\mathrm{F}=4 \mathrm{DS} / 15 \mathrm{AvS} / 4 \mathrm{PvS} ; \mathrm{T}=12-15 \mathrm{AvS} / 7 \mathrm{PvS}$. Ratios $\circ$ : MzL/PzL: 3.90-4.22; PL/TgL: 1.70-1.89. Ratios ${ }^{1}:$ MzL/PzL: 3.65; PL/TgL: 0.82. Brachypterous females and macropterous males, tegmina cover about half the post-pronotum body length (PPBL) in females and reach at least as far as the end of the abdomen in males.

\section{Etymology}

The genus name is formed by the combination of 'Phasmo-' (Latin: Phasma) meaning 'ghost, apparition, spectre', and referring to the Phasmatodea (stick insects) with which the new genus shares a slender and stick-like appearance, and '-mantella' (Latin) which is the diminutive of 'mantis' The proposed genus name also indirectly refers to the unrelated South American genus Phasmomantis which is similar in general appearance. It is feminine in gender.

\section{Differential diagnosis}

The new genus Phasmomantella gen. nov. is morphologically closest to the oriental genus Euchomenella with which it shares a number of morphological traits such as shape of the head, long and slender pronotum (longer than the remaining body in females), adjacent coxal lobes and protibiae with seven posteroventral spines. Spinal formula is similar to that of Euchomenella: $\mathrm{F}=4 \mathrm{DS} / 15 \mathrm{AvS} / 4 \mathrm{PvS} ; \mathrm{T}=$ 12-14AvS/7PvS. In both Phasmomantella gen. nov. and Euchomenella, femoral AvS 10 and 15 are long with four significantly smaller spines of equal size between them. The following differential diagnosis is based on females.

- Euchomenella differs from Phasmomantella gen. nov. by the following characters: more slender prozone with lateral margins strongly curved inwards; tegmina much shorter, covering only about a quarter to $1 / 3$ of the PPBL; abdomen narrower and more elongate; general colour in most cases variations of brown (very rarely green or with greenish hues but not stable throughout development) with two well-defined dark bands transversely crossing the inner side of the profemora and a darkened area near the distal end of the procoxae (Roy 2001).

- Indomenella differs from Phasmomantella gen. nov. by the following characters: smaller (TL: $75 \mathrm{~mm}$ ); eyes slightly more laterally and ventrally bulging; lateral margins of the prozone curved inwards; pronotum shorter than the remaining body; profemora similar to those of Euchomenella; tegmina shorter, covering about $1 / 3$ of the PPBL; abdomen narrower and more elongate. Spinal formula: $\mathrm{F}=$ 4DS/15AvS/4PvS; T = 14AvS/7-8PvS (Ghate \& Mukherjee 2004).

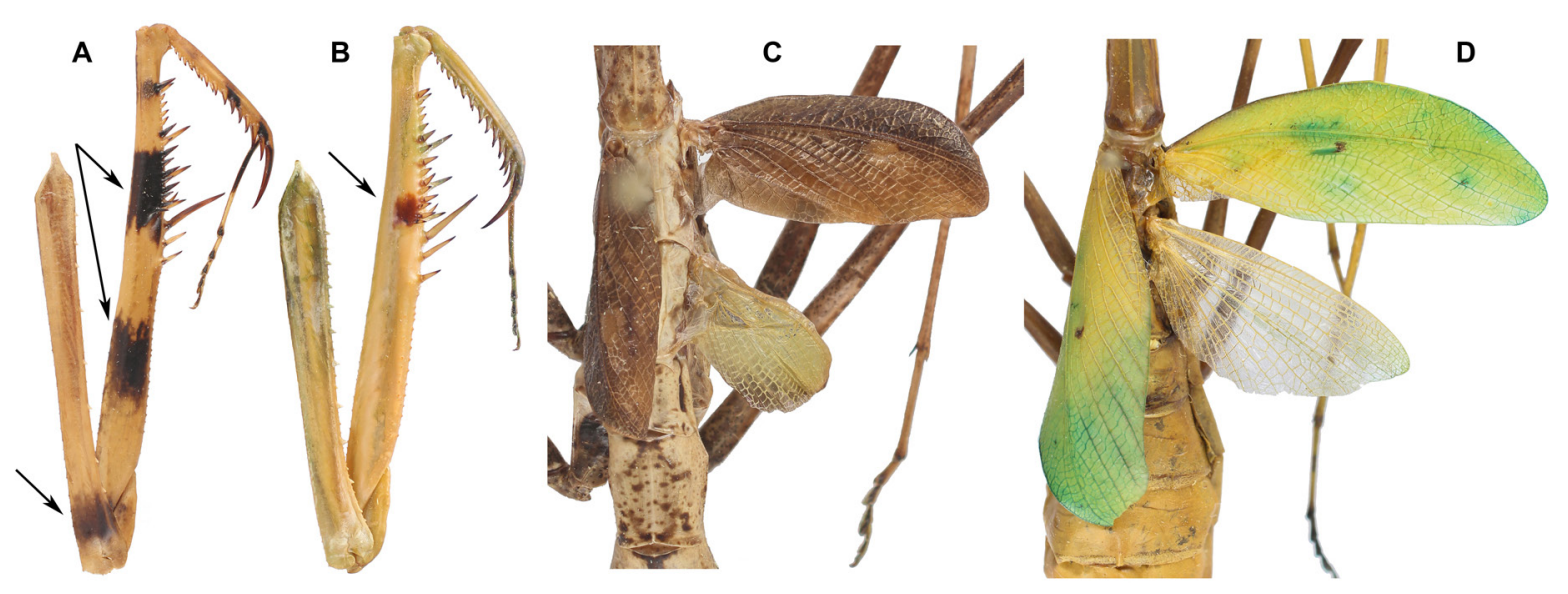

Fig. 2. Side by side comparison in colouration and morphology of the prothoracic legs and wings. A, C. Euchomenella macrops (Saussure, 1870). B, D. Phasmomantella nuichuana gen. et sp. nov., o. Not to scale. 
- Tagalomantis differs from Phasmomantella gen. nov. by the following characters: smaller (TL: 63.4$71.0 \mathrm{~mm}$ ); eyes slightly less bulging laterally; pronotum shorter than the remaining body, with two prominent tubercles behind the supra-coxal sulcus; no spot on the inner side of the profemora; tegmina much shorter, covering about $1 / 4$ of the PPBL; abdomen much narrower and more elongate. Femoral AvS arrangement: IIIIIIIIIIIIIIII with only three short AvS before the most distal spine (Hebard 1920) compared to four in Phasmomantella gen. nov. Spinal formula: $F=4 D S / 16 A v S / 4 P v S ; T=$ 16-18AvS/10-12PvS (Schwarz 2017).

\section{Species included and distribution}

Phasmomantella nuichuana gen. et sp. nov. (Núi Chúa National Park, Vietnam)

Phasmomantella pallida (Roy, 2001) gen. et comb. nov. (Nha Trang, Vietnam)

\section{Key to the species of Phasmomantella gen. nov.}

1. Anterior side of profemur with one irregularly outlined square-shaped spot (reddish brown in preserved specimens) confined between first and fifth anteroventral spine, all spines of prothoracic legs yellowish green, apically infuscate, without small dark spot at the base of first doscoidal spine Phasmomantella nuichuana gen. et sp. nov.

2. Anterior side of profemur with one rectangular black spot, starting anteriorly from first anteroventral spine, ending at fifth anteroventral spine; anteroventral spines 1, 2, 3, 4, 6, 8, 10 and 15 entirely darkened, other spines only apically infuscate, with a small dark spot at the base of first discoidal spine Phasmomantella pallida (Roy, 2001) gen. et comb. nov.

Phasmomantella nuichuana gen. et sp. nov. urn:1sid:zoobank.org:act:BBECB6B7-4623-4711-A730-9B20CC92E34C

Figs 2B, D, 3-4, 6; Table 1

\section{Diagnosis}

Very large species with long and slender pronotum and relatively broad abdomen in females. Head broader than high with large globular eyes. Antennae filiform. Pronotum very finely denticulate along the margins, with more prominent teeth in the prozone, teeth fading away towards the posterior end of the metazone. Medial keel embedded in a longitudinal groove in the prozone but elevated in the metazone. Cervical region with two ventral sclerites. Profemora with four discoidal spines, 15 anteroventral spines and four posteroventral spines. Protibiae with 13 or 14 (rarely 15) anteroventral spines (most proximal spine usually much smaller than the others) and seven posteroventral spines. Tegmina cover about half the PPBL in females. Male unknown.

\section{Etymology}

The species epithet "nuichuana" refers to the original collection locality, Núi Chúa N.P. in southern Central Vietnam.

\section{Type material}

Holotype (Fig. 3)

VIETNAM: + , Ninh Thuan prov., Núi Chúa N.P., $11^{\circ} 42^{\prime}$ N, 10909’ E, 3-9 Aug. 2014, night collecting, GTI project, RBINS mission (IRSNB IG 32.779), J. Constant and J. Bresseel leg.

Paratypes (Fig. 4)

VIETNAM: 3 우, same data as for holotype (RBINS); 1 , same data as for holotype (VNMN). 


\section{Description}

Female (holotype, Fig. 3)

MeAsurements. For details, see Table 1.

HEAD (Fig. 3C). Wider than long with large, rounded compound eyes projecting outside profile of head both laterally and anteriorly. Vertex straight. Ocelli very small. Ocellar tubercle with slightly protruding arch-shaped ridge anteriorly connecting the ocelli. Median ocellus pointing forwards; lateral paired ocelli barely larger and facing sideways. Lower frons transverse and slightly arch-shaped without vertical ridges internally; upper and lateral margins bordered with a protruding ridge. Clypeus entirely smooth.

Thorax (Fig. 3A). Pronotum long, straight and slender. Gradually expanding from rounded anterior margin towards widest point, then narrowing down in gentle sinusoidal curve until margins run parallel to each other, and very slightly widening again near the posterior end. Fine denticulation along lateral margins more prominent in prozone, progressively disappearing towards posterior end of metazone.

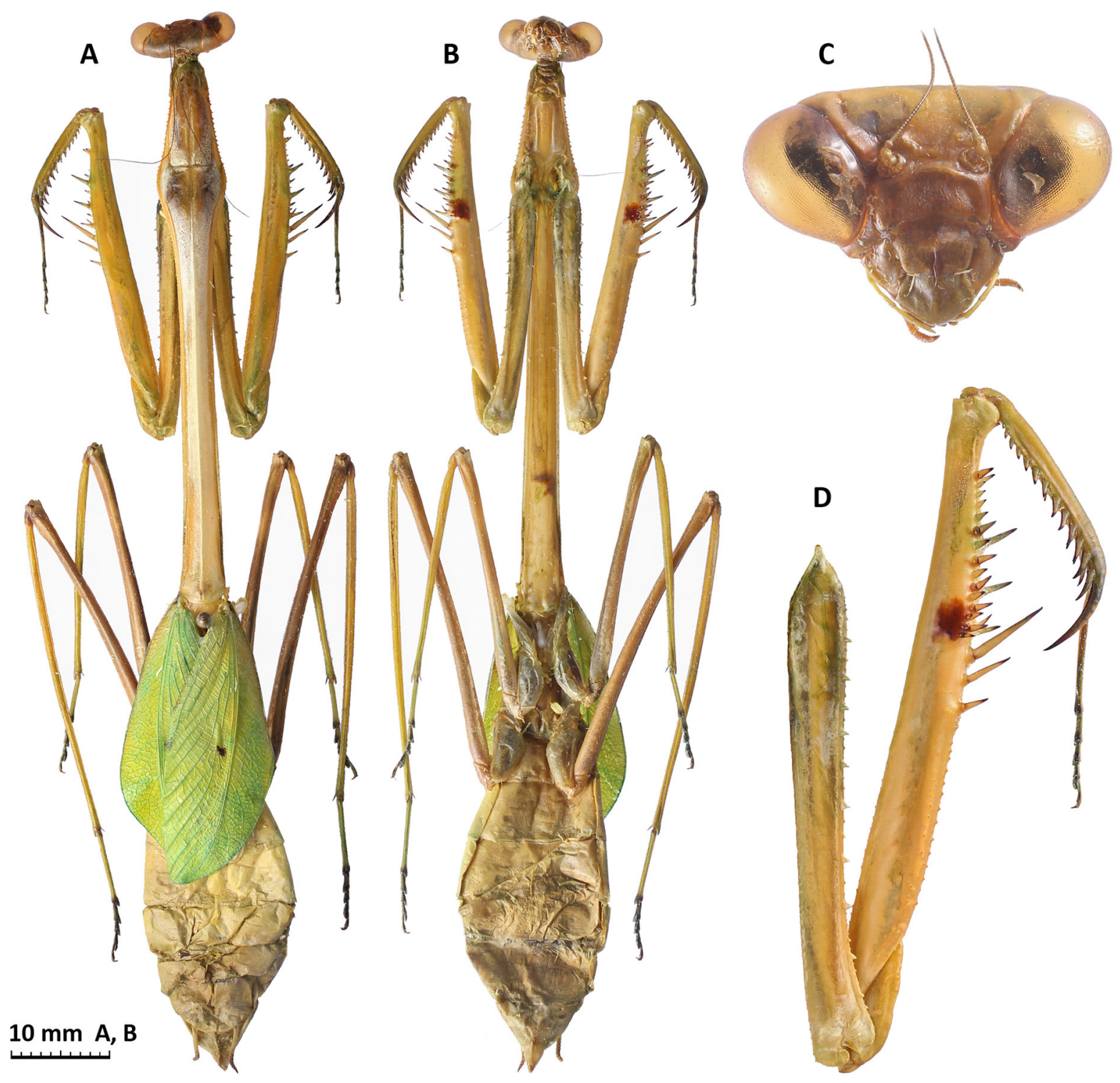

Fig. 3. Phasmomantella nuichuana gen. et sp. nov., holotype, ${ }^{\text {+ }}$. A. Habitus, dorsal view. B. Habitus, ventral view. C. Head, frontal view. D. Left anterior leg, anterior view. C-D not to scale. 
Table 1. Measurements and spine counts for the holotype(HT) and the 4 paratypes (PT) of Phasmomantella nuichuana gen. et sp. nov., placed in the same order as in Fig. 4.

\begin{tabular}{lcccccc}
\hline Measurements & HT & PT 1 & PT 2 & PT 3 & PT 4 & Mean (all types) \\
\hline Total Length & 99.8 & 84.9 & 88.9 & 86.5 & 96.5 & 91.3 \\
Head width & 10.3 & 9.7 & 10.1 & 9.8 & 10 & 10 \\
Head height & 7 & 6.5 & 6.4 & 6.3 & 6.6 & 6.6 \\
Pronotum length & 51.5 & 45.6 & 48.7 & 44.6 & 49.6 & 48 \\
Pronotum width & 6.9 & 6.1 & 6.4 & 6 & 6.4 & 6.4 \\
Pronotum narrow width & 3.1 & 2.7 & 3.1 & 2.5 & 3 & 2.9 \\
Prozone length & 10.2 & 9.1 & 9.5 & 9.1 & 9.5 & 9.5 \\
Metazone length & 41.3 & 36.5 & 39.2 & 35.5 & 40.1 & 38.5 \\
Tegmen length & 27.2 & 25.4 & 26.9 & 26.2 & 26.7 & 26.5 \\
Procoxa length & 24.7 & 21.9 & 23.3 & 21.6 & 23 & 22.9 \\
Profemur length & 29 & 24.9 & 27.4 & 25.5 & 28 & 27 \\
Protibia length & 12.6 & 11.6 & 11.9 & 11.5 & 11.7 & 11.9 \\
Protarsus length & 11.3 & 10.2 & 10.5 & 9.9 & 10.5 & 10.5 \\
Mesofemur length & 23.5 & 21.2 & 21.5 & 21.5 & 24 & 22.3 \\
Mesotibia length & 21.8 & 19.2 & 18.4 & 20 & 22.7 & 20.4 \\
Mesotarsus length & 9.9 & 8.9 & 9.2 & 8.9 & 9.5 & 9.3 \\
Metafemur length & 31.1 & 27.2 & 28.7 & 26.4 & 29.9 & 28.7 \\
Metatibia length & 32.4 & 27.5 & 31 & 28.9 & 31.7 & 30.3 \\
Metatarsus length & 12.9 & 11.8 & 12.2 & 11.5 & 12 & 12.1 \\
Anteroventral femoral spine count & 15 & 15 & 15 & 15 & 15 & \\
Anteroventral tibial spine count & $13 / 14$ & $13 / 14$ & $14 / 15$ & $13 / 14$ & 13 & \\
Posteroventral tibial spine count & 7 & 7 & 7 & 7 & 7 & \\
\hline
\end{tabular}

Dorsal surface entirely smooth. Narrowest point located in the middle of pronotum. Medial keel embedded in a longitudinal groove-like depression in prozone and anterior part of metazone up to widest point but becoming distinctly elevated afterwards. Cross-section of metazone triangular. Cervix with two strongly sclerotized ventral cervical sclerites, lateral cervical sclerites and intercervical sclerites. Postcervical plate elongated and smooth, with two longitudinal folds running parallel to each other between the intercervical sclerites and the forecoxal joints. Furcasternite entirely smooth.

Prothoracic Legs (Fig. 3A-B, D). Coxa slightly shorter than half of pronotum length, with 9 to 10 white spinules of equal size, irregularly alternated with one to four even smaller spinules in between them. Coxal lobes rounded, equal in length and adjacent, occasionally with a small space between them. Femur with straight dorsal margin, surface entirely smooth apart from two parallel rows of small tubercles that run ventrally and start proximally from $2^{\text {nd }}$ discoidal spine towards distal part of joint with trochanter. Femoral brush long and narrow in shape, starting from AvS 13 and ending just a little distally of AvS 15. Colouration green with exception of a well-defined, but irregularly outlined square-shaped spot on the anterior surface situated between boundaries of four most proximal AvS. Femoral spot reaches from ventral margin to roughly two-thirds of femoral height, reddish brown in dried specimens. Small discolourations of same colour as femoral spot are present at base of AvS 2, 4, 6, 8, 10 and 15, but are hard to distinguish by naked eye. Discolouration of most distal AvS very small, larger ones at base of AvS 2 to 4, overlapping with femoral spot. Tibial spur groove around distal third of femur. AvS unequal in size and arranged as follows: IIIIIIIIIIIIII. All spines yellowish green, apically infuscate. AvS 10 


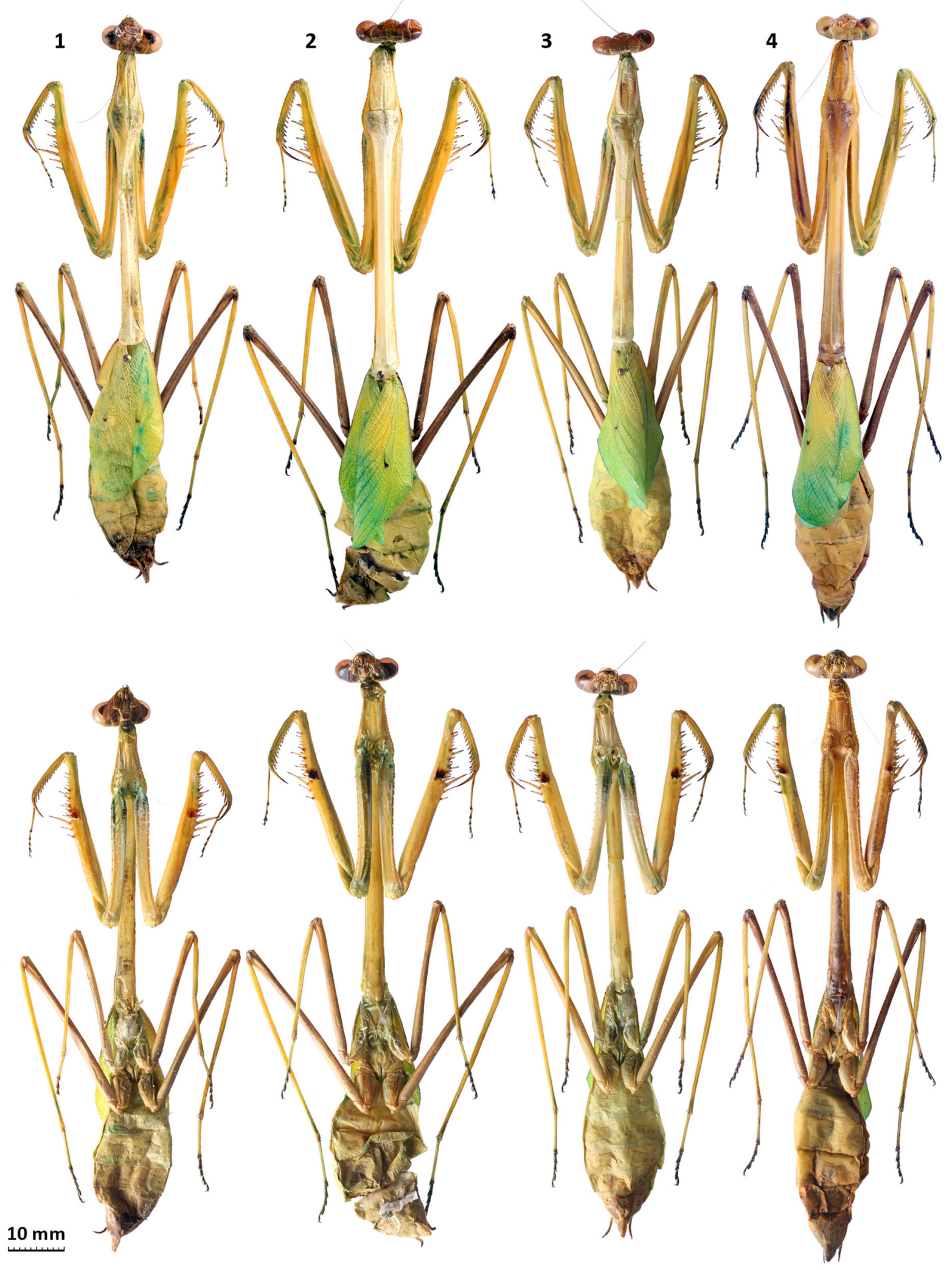

Fig. 4. Phasmomantella nuichuana sp. nov., dorsal and ventral views of paratypes 1-4. 
and 15 large but with four much smaller spines of equal size between them. Large and medium spines alternate between AvS 1 and 10, first spine being a medium one. Medium spines subtly inclined towards anterior side of femur. PvS 4 is smallest, 3 is largest, 1 and 2 larger than $4^{\text {th }}$, but gradually becoming smaller towards proximal end of femur. DS with same size arrangement as PvS, with DS 3 remarkably large and about twice the size of PvS 2. Protibiae smooth with longitudinal groove across entire length of posterior side. Tibial AvS gradually elongated towards tibial spur; PvS more procumbent. Protarsi apically darkened; first tarsomere longer than others combined. Spinal formula: F $=4 \mathrm{DS} / 15 \mathrm{AvS} / 4 \mathrm{PvS}$; $\mathrm{T}=13-15 \mathrm{AvS} / 7 \mathrm{PvS}$.

Meso- And metathoracic Legs (Fig. 3A-B). Long and slender, densely setose across entire surface. Meso- and metafemora distinctly darker and brownish as compared to greenish tibiae. Femora with ventral (posterior) and dorsal (anterior) carina, rounded genicular lobes and a short genicular spur. Tibiae tubular with two tibial spurs. Tarsi 5-segmented and apically darkened. First tarsomere of mesotarsus as long as (and in the metatarsus slightly longer than) remaining segments combined.

Tegmina and alae (Fig. 3A). Covering about half the PPBL, entirely opaque and uniformly green, reaching about halfway on tergite 4. Costal area gradually broadening and reaching widest point just past half length of tegmen, right after stigma. Veins and stigma green. Stigma long and narrow, situated at about half total length of tegmen; small black spot located at distal end of stigma and often partially encompassing the latter at its posterior side. Alae only slightly shorter than tegmina when folded and entirely hyaline.

ABDOMEN (Fig. 3A-B). Much broader than rest of body, reaching widest point around tergite 4 before a gradual posterior narrowing. Ventrally and dorsally uniformly green/yellowish. Tergite 10 broad, short and rounded.

\section{Distribution}

Currently recorded only from Núi Chúa N.P. in Ninh Thuan Province, southern Central Vietnam (Fig. 6).

Phasmomantella pallida (Roy, 2001) gen. et comb. nov. Figs 5-6; Table 2

\section{Diagnosis}

Species with long and slender pronotum. Head broader than high, with large globular eyes. Antennae filiform. Pronotum entirely smooth along the margins. Medial keel embedded in a longitudinal groove in the prozone but elevated in the metazone. Profemora with four discoidal spines, 15 anteroventral spines and four posteroventral spines. Protibiae with 12 anteroventral spines and seven posteroventral spines. Tegmina and alae entirely hyaline, reaching apex of abdomen in males. Female unknown.

\section{Etymology}

The specific epithet 'pallida' was proposed by Roy (2001) when he described the species as Euchomenella pallida since the colouration of the type was uniformly beige and far more pale than in any other species belonging to that genus. By analogy with Phasmomantella nuichuana gen. et sp. nov., it is now clear that the live colouration is green, turning to beige when pigmentation is lost during conservation.

\section{Material examined}

Holotype (Fig. 5)

VIETNAM: đ̃, Khánh Hòa Prov., Nha Trang, 19-20 Jun. 1912, A. Krempf leg. (MNHN (EP) 2519, genitalia preparation $\mathrm{n}^{\circ} 3627$ by R. Roy). 
Table 2. Measurements and spine counts for the holotype (HT) of Phasmomantella pallida (Roy, 2001).

\begin{tabular}{lc}
\hline Measurements & HT \\
\hline Total Length & 49.4 \\
Head width & 5.6 \\
Head height & 2.8 \\
Pronotum length & 21.4 \\
Pronotum width & 2.7 \\
Pronotum narrow width & 1.3 \\
Prozone length & 4.6 \\
Metazone length & 16.8 \\
Tegmen length & 26.1 \\
Procoxa length & 11.6 \\
Profemur length & 13.4 \\
Protibia length & 6 \\
Protarsus length & 5.2 \\
Mesofemur length & 11.3 \\
Anteroventral femoral spine count & 15 \\
Anteroventral tibial spine count & 12 \\
Posteroventral tibial spine count & 7 \\
\hline
\end{tabular}

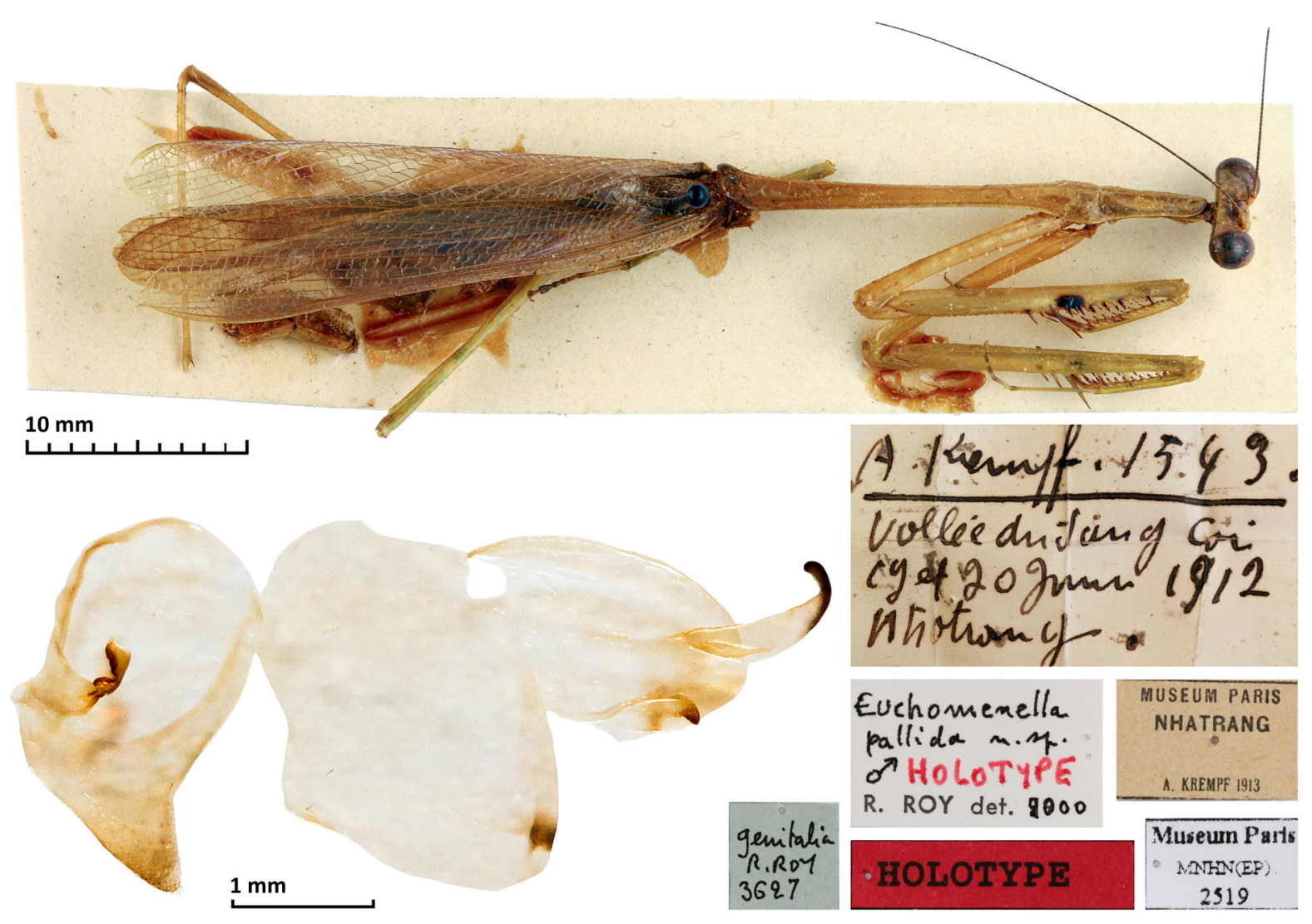

Fig. 5. Phasmomantella pallida (Roy, 2001), holotype, $\widehat{\partial}$, habitus (glued on paper), genitalia (preparation by Roger Roy nr: 3627) and labels. 


\section{Description}

Male (holotype, Fig. 5)

MEASUREMENTS. For details, see Table 2.

HEAD (Fig. 5). Wider than long with large, rounded compound eyes projecting outside profile of head both laterally and anteriorly. Vertex more or less straight. Ocelli well developed, ocellar tubercle flat with only the ocelli protruding. Median ocellus pointing forwards, lateral paired ocelli larger and facing sideways. Lower frons transverse and slightly arch-shaped without vertical ridges internally; upper and lateral margins bordered with a noticeably protruding ridge. Clypeus entirely smooth.

Thorax (Fig. 5). Pronotum long, straight and slender. Gradually expanding from rounded anterior margin towards widest point, then narrowing down in gentle sinusoidal curve until margins run parallel to each other, and very slightly widening again near the posterior end. Lateral margins and dorsal surface entirely smooth. Narrowest point located in the middle of pronotum. Medial keel embedded in a longitudinal groove-like depression in prozone and anterior part of metazone up to widest point but becoming distinctly elevated afterwards. Cross-section of metazone triangular. Furcasternite entirely smooth.

Prothoracic Legs (Fig. 5). Coxa slightly shorter than half of pronotum length, with 8 or 9 white spinules of equal size without smaller spinules in between them. Coxal lobes rounded, equal in length but ventral lobe broader, running parallel with a small space between them. Femur with straight dorsal margin, surface entirely smooth apart from two parallel rows of small tubercles that run ventrally and start proximally from $2^{\text {nd }}$ discoidal spine towards distal part of joint with the trochanter. Femoral brush long and oval in shape, starting from the $12^{\text {th }}$ and ending just a little distally of $15^{\text {th }}$ AvS. Colouration beige with some green hues (probably green during life) with exception of a well-defined rectangular spot on the anterior surface starting proximally from the $1^{\text {st }} \mathrm{AvS}$ and ending between the $4^{\text {th }}$ and $5^{\text {th }} \mathrm{AvS}$. Femoral spot reaches from ventral margin to roughly half of femoral height, deep black in dried specimens. AvS $1,2,3,4,6,8,10$ and 15 entirely darkened, other AvS only apically infuscate. Tibial spur groove past distal third of femur. AvS unequal in size and arranged as follows: IIIIIIIIIIIIII. AvS 10 and 15 large but with four much smaller spines of equal size between them. Large and medium spines alternate between AvS 1 and 10, first spine being a medium one. Medium spines subtly inclined towards anterior side of femur. PvS 4 is smallest, 3 is largest, 1 and 2 larger than the $4^{\text {th }}$ but gradually becoming smaller towards proximal end of femur. First DS with dark brownish spot at the base. DS with same size arrangement as PvS, with DS 3 remarkably large and about twice the size of second PvS. Protibiae smooth with longitudinal groove across entire length of posterior side. Tibial AvS gradually elongated towards tibial spur. Protarsi apically darkened; first tarsomere longer than others combined. Spinal formula: $F=$ 4DS/15AvS/4PvS; T = 12AvS/7PvS.

MESO- AND METATHORACIC LEGS (Fig. 5). Long and slender without lobes. Femora with rounded genicular lobes and a short genicular spur. Tibiae tubular with two tibial spurs. First tarsomere of mesotarsus slightly shorter than the remaining segments combined.

Tegmina and Alae (Fig. 5). Slightly longer than pronotum, possibly extending a little further than posterior end of abdomen (damaged abdomen in holotype), costal and discoidal area entirely hyaline with darker brownish veins. Costal area very narrow, reaching widest point about halfway between wing base and stigma. Stigma triangular, long and narrow, broad anteriorly, but ending in a sharp point posteriorly; entirely transparent, but well defined and protruding from the surface of tegmen; situated at about a third of total tegmen length. Alae as long as tegmina when folded, entirely hyaline but very slightly enfumated (beige-brown) with darker veins than in tegmina.

ABdomen (Fig. 5). Long and narrow. Damaged and incomplete in holotype due to genitalia preparation. tergite 10 broad, short and rounded. 


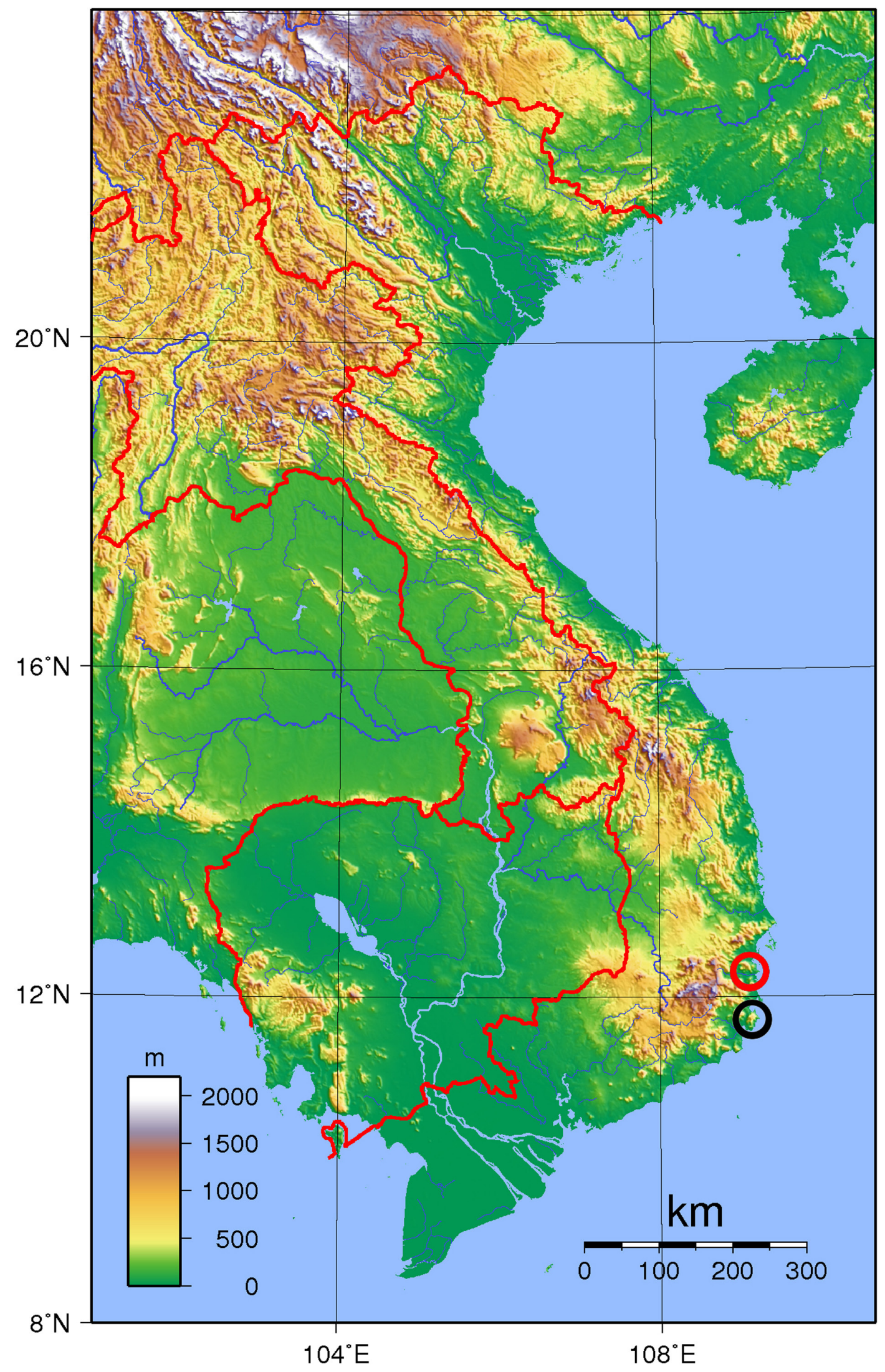

Fig. 6. Distribution map of Phasmomantella nuichuana gen. et sp. nov. (black circle) and Phasmomantella pallida (Roy, 2001) (red circle). 
Genitalia (Fig. 5). A brief description of the genitalia is provided by Roy (2001) along with a partial drawing. It translates as follows: "Hypophallus with a more or less square shaped darker region on the left side of the apex, possibly incomplete. Right epiphallus gradually more brown towards the apical side. Phalloid apophysis with brown apex and small lobe".

\section{Distribution}

Currently recorded only from Nha Trang in Khánh Hòa Province, southern Central Vietnam (Fig. 6).

\section{Discussion}

\section{Taxonomic considerations}

The genus Phasmomantella gen. nov. is placed within the recently reinstated tribe Euchomenellini of the subfamily Deroplatyinae, along with Euchomenella, Indomenella and Tagalomantis, based on a morphological similarity with Euchomenella. Phasmomantella gen. nov. has much larger wings in females compared to the other genera and has an overall green colouration, which is atypical for the tribe. The classification of oriental stick-shaped mantises remains largely unresolved, although recent phylogenetic (Svenson \& Whiting 2004, 2009) and morphologic evidence (Roy 2001, 2008; Shcherbakov 2012; Schwarz \& Helmkampf 2014) supports a separation of the abovementioned genera from the now exclusively neotropical subfamily Angelinae Beier, 1964 to the oriental subfamily Deroplatyinae.

\section{Núi Chúa National Park and surrounding areas}

Phasmomantella nuichuana gen. et sp. nov. is currently know from Núi Chúa N.P. only. The park is located in the hottest and driest part of the Ninh Thuận province and borders the south Central Vietnamese coast. It covers 22513 ha of land and 7352 ha of marine area. The altitude ranges from sea level to an

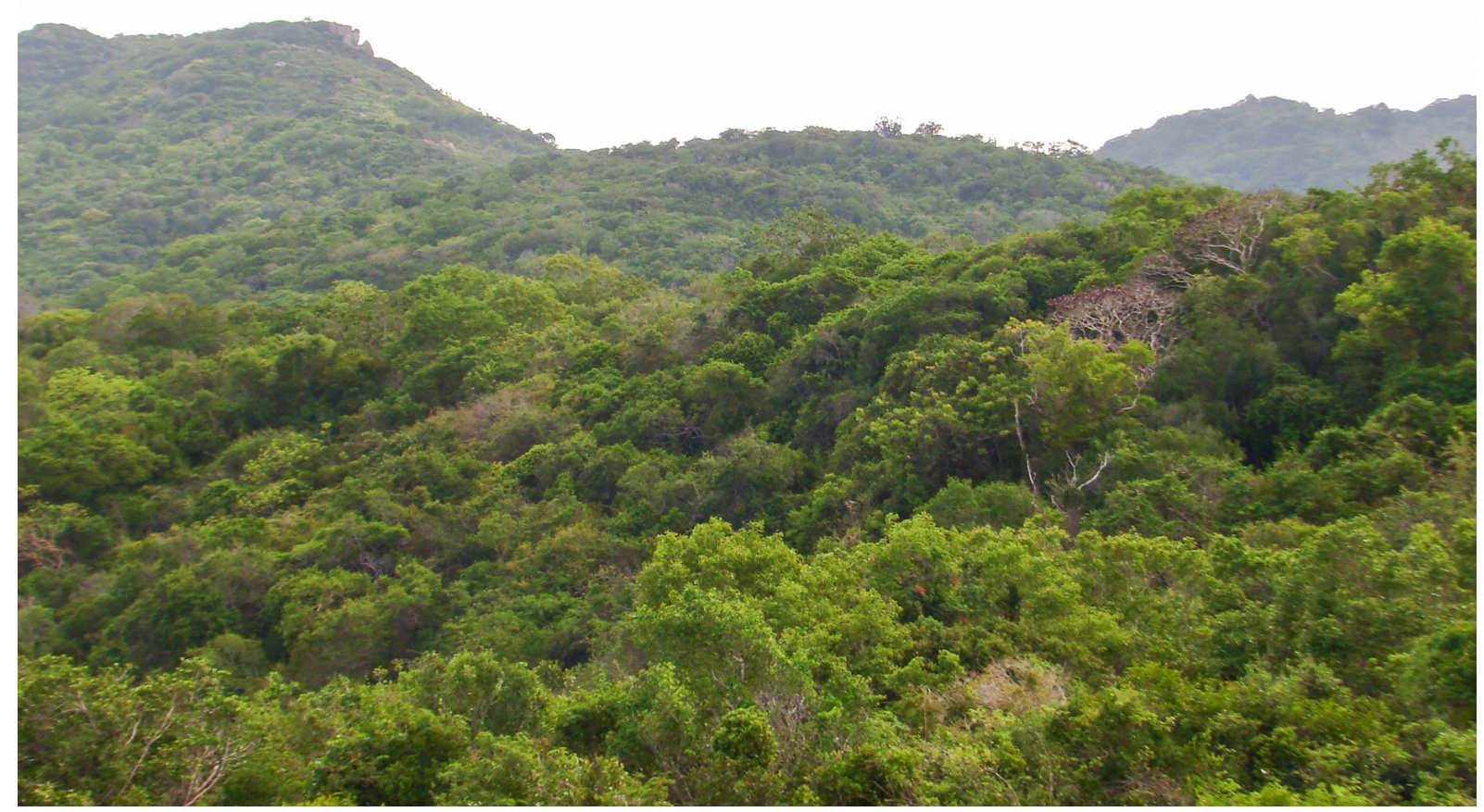

Fig. 7. Panoramic view of the disturbed secondary rainforest at the collection site in Núi Chúa N.P. 
elevation of $1039 \mathrm{~m}$ on mount Núi Chúa. The park houses six types of habitats of which the evergreen secondary forest covers roughly one third of the total surface. In its lower parts, Núi Chúa N.P. serves as a cultivation ground for agriculture purposes and mainly consists of a hot and dry climate area where thorny trees and bushes thrive. Above $800 \mathrm{~m}$ altitude, a humid closed-canopy rainforest is present. The most prolific collecting sites were small open patches in the secondary disturbed rainforest at an elevation below $350 \mathrm{~m}$ (Fig. 7), which were occasionally encountered while trekking up the mountain on long and narrow trails bordered with dense vegetation on both sides. Two nights of collecting in this part of the park yielded the five adult female specimens described in this paper. Additional information is needed to confirm whether or not P. nuichuana gen. et sp. nov. is endemic to the forests on Mount Núi Chúa. Phasmomantella pallida gen. et comb. nov. was collected more than 100 years ago about $60 \mathrm{~km}$ North of Núi Chúa N.P. in what is now a heavily urbanised region. It is unclear whether or not the species is currently still present in the remaining patches of forest surrounding Nha Trang. Our knowledge on the distribution and species diversity of Phasmomantella gen. nov. is largely incomplete. The unique biogeography of the region where Phasmomantella gen. nov. was discovered is characterised by strong topographic, climatic and ecologic boundaries within relatively small distances. The resulting insularlike biogeography causes a high level of speciation and endemism around the mountain tops where wet rainforest remains. This has been observed and confirmed for many species of stick- and leaf insects (Joachim Bresseel and Jérôme Constant pers. comm.). This means that in theory each mountain top can have its own unique species, since no gene flow is possible between populations. Núi Chúa N.P. and surrounding areas are still under-researched and likely to harbour a large number of new species and genera that merit further investigation. The protection and sustainable management of valuable ecosystems such as Núi Chúa N.P. remains a priority to ensure the preservation of a unique biodiversity for future generations.

\section{Natural history}

Currently, very little is known on the biology of the species of Phasmomantella gen. nov. apart from the fact that they inhabit forest habitats. Possible colour variations in wild populations are unknown, although the green colouration seems to be constant. Interestingly, other members of the tribe Euchomenellini are usually brown and smaller in size. New data on this remarkable genus may expand our knowledge on mantodean evolution and specific adaptations that praying mantises develop in response to their environment.

\section{Acknowledgments}

I wish to thank Roger Roy for the pleasant and insightful correspondence and for hosting my visit to the MNHN collections to study additional specimens of Euchomenellini, including the type of P. pallida. I also wish to express my gratitude to Jérôme Constant and Joachim Bresseel (RBINS) for their friendship, help and support. Jérôme Constant also provided the distribution map and a photograph of the collection site. The present paper is a result of the project 'A step further in the Entomodiversity of Vietnam', supported through a grant issued by the capacity building Programme of the Belgian Global Taxonomy Initiative National Focal Point that runs under the CEBioS programme with financial support from the Belgian Directorate-General for Development Cooperation (DGD).

\section{References}

Brannoch S.K., Wieland F., Rivera J., Klass K.D., Béthoux O. \& Svenson G.J. 2017. Manual of praying mantis morphology, nomenclature, and practices (Insecta, Mantodea). ZooKeys 696: 1-100. https://doi.org/10.3897/zookeys.696.12542

Ghate H.V. \& Mukherjee T.K. 2004. First report of the praying mantis genus Euchomenella GiglioTos from India and description of Euchomenella indica n. sp. from South India (Insecta : Mantodea : Mantidae: Angelinae). Genus 15 (3): 329-337. 
Giglio-Tos E. 1916. Mantidi esotici, generi e specie nuove. Bullettino della Società Entomologica Italiana 47: 35-36. Available from https://biodiversitylibrary.org/page/10449248 [accessed 30 May 2018].

Giglio-Tos E. 1927. Orthoptera Mantidae. In: Schulze F.E. \& Kükenthal W. (eds) Das Tierreich, eine Zusammenstellung und Kennzeichnung der rezenten Tierformen. Fascicle 50. de Gruyter \& Co, Berlin \& Leipzig.

Hebard M. 1920. Studies in Malayan, Papuan, and Australian Mantidae. Proceedings of the Academy of Natural Sciences of Philadelphia 72: 38.

Roy R. 2001. Contribution à la connaissance des Angelinae de la région orientale: les genres Euchomenella, Mythomantis et Tagalomantis (Dictyoptera, Mantidae). Revue française d'Entomologie (N.S.) 23 (1): 79-92.

Roy R. 2008. Indomenella, nouveau genre d'Angelinae (Dict. Mantidae). Bulletin de la Société entomologique de France 113: 330.

Schwarz C.J. 2017. Update on Tagalomantis manillensis (Saussure), with description of the female and comments on its systematic placement and life history (Insecta: Mantodea: Deroplatyinae). Stuttgarter Beiträge zur Naturkunde A, Neue Serie 10: 19-39. https://doi.org/10.18476/sbna.v10.a2

Schwarz C.J. \& Helmkampf M.E. 2014. A remarkable new species of Mythomantis Giglio-Tos, 1916 from northern Borneo, with notes on the systematics of Deroplatyinae Westwood, 1889 (Mantodea: Mantidae). Zootaxa 3797: 120-129. https://doi.org/10.11646/zootaxa.3797.1.11

Shcherbakov E.O. 2012. New data on the genera Euchomenella and Tagalomantis (Dictyoptera: Mantidae: Angelinae). Zoosystematica Rossica 21 (2): 270-278.

Svenson G.J. 2014. Revision of the Neotropical bark mantis genus Liturgusa Saussure, 1869 (Insecta, Mantodea, Liturgusini). ZooKeys 390: 1-214. https://doi.org/10.3897/zookeys.390.6661

Svenson G.J. \& Whiting M.F. 2004. Phylogeny of Mantodea based on molecular data: evolution of a charismatic predator. Systematic Entomology 29: 359 - 370.

https://doi.org/10.1111/j.0307-6970.2004.00240.x

Svenson G.J. \& Whiting M.F. 2009. Reconstructing the origins of praying mantises (Dictyoptera, Mantodea): the role of Gondwanan vicariance and morphological convergence. Cladistics 25: 468-514. https://doi.org/10.1111/j.1096-0031.2009.00263.x

Wieland F. 2013. The Phylogenetic System of Mantodea (Insecta: Dictyoptera). Species, Phylogeny and Evolution 3 (1), Universitätsverlag Göttingen (SPE), Göttingen.

Manuscript received: 8 June 2017

Manuscript accepted: 9 January 2018

Published on: 7 June 2018

Topic editor: Gavin Broad

Desk editor: Kristiaan Hoedemakers

Printed versions of all papers are also deposited in the libraries of the institutes that are members of the EJT consortium: Muséum national d'Histoire naturelle, Paris, France; Botanic Garden Meise, Belgium; Royal Museum for Central Africa, Tervuren, Belgium; Natural History Museum, London, United Kingdom; Royal Belgian Institute of Natural Sciences, Brussels, Belgium; Natural History Museum of Denmark, Copenhagen, Denmark; Naturalis Biodiversity Center, Leiden, the Netherlands; Museo Nacional de Ciencias Naturales-CSIC, Madrid, Spain; Real Jardín Botánico de Madrid CSIC, Spain; Zoological Research Museum Alexander Koenig, Bonn, Germany. 